\title{
Evaluasi Kurva Noise Power Spectrum (NPS) dari Citra CT Scan dengan Variasi Faktor Eksposi
}

\author{
Doharmansyah Putra $^{1}$, Ni Larasati Kartika Sari ${ }^{*}$, Puji Hartoyo ${ }^{1}$ \\ ${ }^{1}$ Program Studi Fisika, Fakultas Teknik dan Sains, Universitas Nasional, Jakarta \\ *Korespondensi penulis: nilarasati@civitas.unas.ac.id
}

\begin{abstract}
Abstrak. Penelitian ini menganalisis kualitas citra CT-Scan berupa noise yang diukur dengan menggunakan metode NPS. (Noise Power Spectrum). Citra CT-Scan didapatkan dengan menggunakan CT-Scan merk siemens somatom emoticon dengan menggunakan solid water phantom dan variasi faktor eksposi $80 \mathrm{kVdan} 130 \mathrm{kV}$ dengan variasi mAs 100 mAs, 150 mAs, 200 mAs, 250 mAs, 300 mAs. Program pengukuran NPS dilakukan dengan menerapkan transformasi fourier pada 4 Region of Interent (ROI) homogen di citra. Program pengukuran NPS dikembangkan dengan software matlab. Hasil penelitian menunjukan bahwa kurva NPS berbentuk parabola, dimana terdapat 2 kemiringan. Kemiringan tersebut merupakan hasil dari filtering yang dilakukan oleh algoritma rekonstruksi pada sistem reknstruksi citra CT-Scan. Selain itu tinggi puncak kurva NPS juga dipengaruhi oleh nilai kV dan mAs. Semakin tinggi nilai $\mathrm{kV}$ dan $\mathrm{mAs}$ yang diberikan maka puncak kurva NPS yang didapatkan semakin rendah. Luas di bawah kurva NPS merupakan nilai varians $\left(\sigma^{2}\right)$, sehingga hal ini menunjukan semakin tinggi $\mathrm{kV}$ dan $\mathrm{mAs}$ semakin rendah tingkat noise.
\end{abstract}

Kata kunci: standar deviasi, transformasi fourier, varians, noise power .spectrum

\begin{abstract}
This study analyzes CT-Scan image quality in the form of noise using NPS (Noise Power Spectrum) method. CT-Scan images were obtained in Siemens somatom emoticon CT-Scan using solid water phantom and variation of exposure factor $80 \mathrm{kV}$ and $130 \mathrm{kV}$ with $\mathrm{mAs}$ variation of $100 \mathrm{mAs}, 150 \mathrm{mAs}, 200 \mathrm{mAs}, 250 \mathrm{mAs}, 300 \mathrm{mAs}$. The NPS measurement was performed by applying fourier transforms to 4 homogenous Region of Interest (ROI). The NPS measurement program was developed with Matlab software. The results showed that the NPS curve is parabolic, where there are 2 slopes. The slope is the result of the filtering performed by the reconstruction algorithm on the CT-Scan's image reconstruction system. In addition, the peak height of the NPS curve is also influenced by the values of $k V$ and $m A s$. The higher the value of $k V$ and $m A$ s given the lower the NPS curve obtained. The area under the NPS curve is proportional to the variance $\left(\sigma^{2}\right)$, so it shows that the higher the $k V$ and $m A$ s the lower the noise level.
\end{abstract}

Keywords: standard deviation, fourier transform, variance, noise power spectrum

\section{PENDAHULUAN}

Beban kerja pesawat Computed Tomography Scan (CT-Scan) di Instalasi Radiologi cukup tinggi, sehingga harus dibarengi kendali kontrol (quality control) yang rutin tiap bulannya. Salah satu komponen dalam quality control CT-Scan adalah kualitas citra. Evaluasi kualitas citra pada CT Scan penting untuk memastikan kualitas diagnostik [1]. Terdapat beberapa indikator untuk mengevaluasi kualitas citra CT-Scan, diantaranya Spatial resolution, contrast resolution, distorsi, artefak, dan noise [2].

Pengukuran Noise pada citra umumnya dilakukan dengan mengukur Signal To Noise Ratio (SNR). Pengukuran noise dengan SNR dengan perubahan faktor eksposi didapat bahwa semakin tinggi tegangan yang diberikan makan nilai SNR yang didapatkan semakin besar, menunjukkan hasil citra dengan kualitas yang baik [3]. Selain dengan metode SNR, pengukuran tingkat Noise pada citra juga dapat dilakukan dengan NPS (Noise Power Spectrum ). NPS adalah ukuran yang berguna memberikan deskripsi noise yang lebih 
lengkap daripada standar deviasi sederhana. NPS menggambarkan variasi noise sebagai fungsi dari frekuensi spasial dan ciri khas tekstur noise [4].

Nilai NPS berbanding terbalik dengan banyaknya jumlah fluence sinar-X yang datang, yang juga berbanding dengan dosis radiasi sehingga pengukuran NPS pada kondisi klinis sangat diperlukan [5]. Grafik NPS selain menggambarkan tekstur noise pada frekuensi spatial, luas area dibawah grafik NPS juga sebanding dengan standar deviasi kuadrat $(\sigma)$ [6]. Perhitungan NPS secara lokal dipengaruhi oleh beberapa faktor, diantaranya banyaknya ROI (Region of Interest), posisi ROI, dan ukuran ROI [7]. NPS pada pemeriksaan Cone Beam CT payudara menunjukkan ketergantungan terhadap ukuran matriks, ukuran piksel, algoritma rekonstruksi, koreksi hamburan dan faktor eksposi [8]. Penggunaan dua algoritma rekonstruksi, SAFIRE (sinogram affirmed iterative reconstruction) dan ADMIRE (advanced modelled iterative reconstruction) pada pesawat CT Scan yang sama, menunjukkan perbedaan kualitas citra dalam hal MTF (Modulation Transfer Function) dan NPS. Kualitas citra lebih baik saat menggunakan ADMIRE dibanding SAFIRE [9]. Perbedaan kernel filter juga mempengaruhi nilai NPS, semakin tajam kernel filter yang digunakan (B70 dan B80), noise yang dihasilkan semakin mengarah ke spasial frekuensi yang lebih tinggi [10].

Seiring dengan perkembangan teknologi CT-Scan yang salah satunya menggunakan banyak detektor dan algoritma rekontrusksi yang lebih rumit [2]. Yang juga berkontribusi pada noise citra. Dengan NPS fisikawan medik dapat mengevaluasi noise lebih lengkap baik dari segi besarnya noise dan tekstur noise. Oleh karena itu penulis menggambil tema analisis noise hasil citra CT dengan metode NPS.

\section{METODE PENELITIAN}

Peralatan yang digunakan dalam penelitian ini adalah dengan menggunakan pesawat CTScan Merk : Somatom emotion 16, Seri : 86669, type tabung : DURA 422 MV, Tegangan Tabung: $130 \mathrm{kV}$ seperti pada gambar 1a., Monitors : Dual TFT LCD, Workstation : HP8200 Linux, dan Solid waterphantom siemens, seperti pada gambar $1 \mathrm{~b}$.

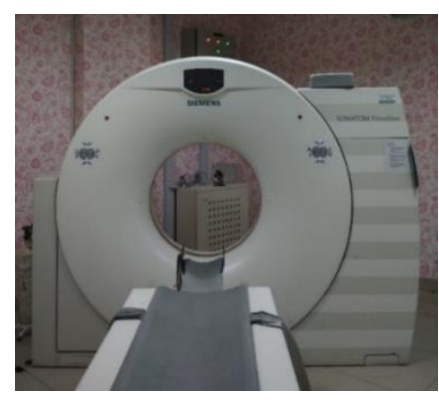

(a)

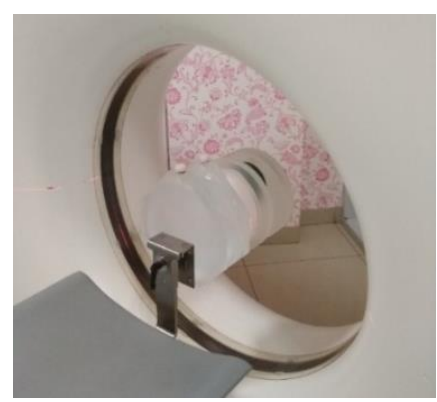

(b)

GAMBAR 1. Peralatan yang digunakan: a). CT-Scan Siemens Somatom emotion 16 Slice, b). Solid Water Phantom.

Kurva NPS (Noise Power Spectrum) dibuat dengan menggunakan software Matlab 2013a. Langkah pertama adalah dengan membuat 4 ROI (Region Of Interest) dengan ukuran matriks $256 \times 50$ piksel. Langkah selanjutnya adalah mencari nilai piksel rata-rata dari keempat ROI tersebut dan menerapkan transformasi Fourier untuk memperoleh nilai NPS dan frekuensi spasial. Kurva NPS terhadap frekuensi spasial ditampilkan dengan satuan piksel dan siklus $/ \mathrm{mm}$, serta $\mathrm{mm}^{2}$ dan siklus $/ \mathrm{mm}$.

\section{HASIL DAN PEMBAHASAN}

Variasi pertama pengambilan data dilakukan dengan menggunakan faktor eksposi $80 \mathrm{kv}$ dan variasi mAs $100 \mathrm{mAs}, 150 \mathrm{mAs}, 200 \mathrm{mAs}, 250 \mathrm{mAs}, 300 \mathrm{mAs}$. Gambar 2a. merupakan 
hasil ROI citra yang diambil dari citra Phantom pada gambar 1b. Gambar 2b hingga e merupakan citra dari Phantom yang sama diambil dengan faktor eksposi $80 \mathrm{kV}$ dan secara berurutan $150 \mathrm{mAs}, 200 \mathrm{mAs}, 250 \mathrm{mAs}$ dan $300 \mathrm{mAs}$. Pada kelima citra terlihat bahwa perubahan $\mathrm{mAs}$ menghasilkan perubahan tekstur noise.

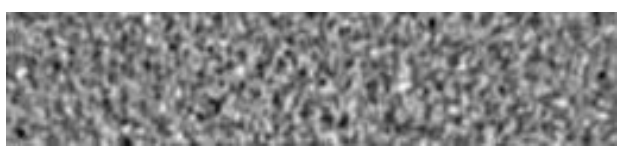

(a)

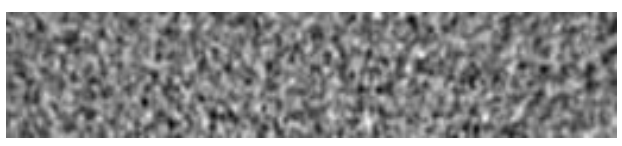

(c)

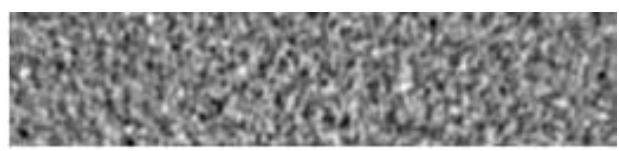

(b)

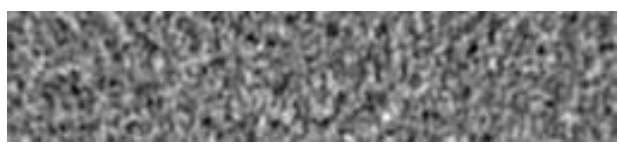

(d)

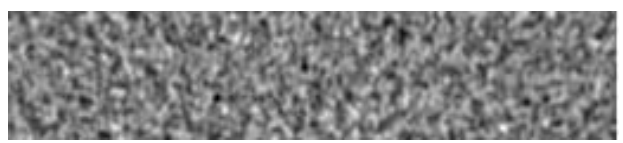

(e)

GAMBAR 2. Hasil Citra sampel yang dipotong dengan ukuran 256x50 a). $80 \mathrm{kV} 100 \mathrm{mAs}, \mathrm{b}) .80 \mathrm{kV} 150$ mAs, c). $80 \mathrm{kV} 200 \mathrm{mAs}, \mathrm{d}) .80 \mathrm{kV} 250 \mathrm{mAs}, \mathrm{e}) .80 \mathrm{kV} 300 \mathrm{mAs}$.

Selanjutnya, dilakukan pengukuran NPS dengan melakukan transformasi fourier pada ratarata nilai piksel di tiap ROI. Kurva hasil pengukuran nps dapat dilihat pada gambar 3 . sumbu X merupakan nilai dari NPS dan sumbu Y merupakan spatial frequency. Kurva pada gambar 3 merupakan kurva NPS dengan satuan piksel.

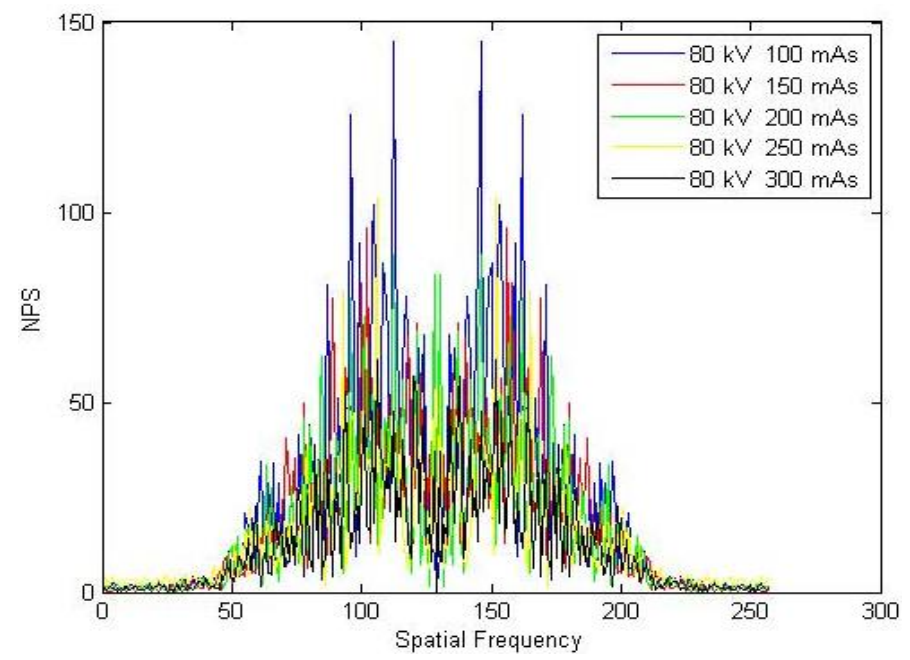

GAMBAR 3. Kurva noise power spectrum (NPS) terhadap spatial frequency.

Kurva NPS juga dapat dinyatakan dengan satuan NPS $\mathrm{mm}^{2}$ dan satuan spatial frequency cycle $/ \mathrm{mm}^{2}$ seperti pada gambar 4 .

Variasi selanjutnya pengambilan data dilakukan dengan menggunakan faktor eksposi 130 $\mathrm{kV}$ dan variasi mAs $100 \mathrm{mAs}, 150 \mathrm{mAs}, 200 \mathrm{mAs}, 250 \mathrm{mAs}, 300 \mathrm{mAs}$. Gambar 5a. merupakan hasil ROI citra yang diambil dari citra Phantom pada gambar 1b. Gambar $5 \mathrm{~b}$ hingga e merupakan citra dari Phantom yang sama diambil dengan faktor eksposi $130 \mathrm{kV}$ dan secara berurutan $150 \mathrm{mAs}, 200 \mathrm{mAs}, 250 \mathrm{mAs}$ dan $300 \mathrm{mAs}$. Pada kelima citra terlihat bahwa perubahan $\mathrm{mAs}$ menghasilkan perubahan tekstur noise. 
(p) ISSN 1410-8682

(e) ISSN 2621-9239

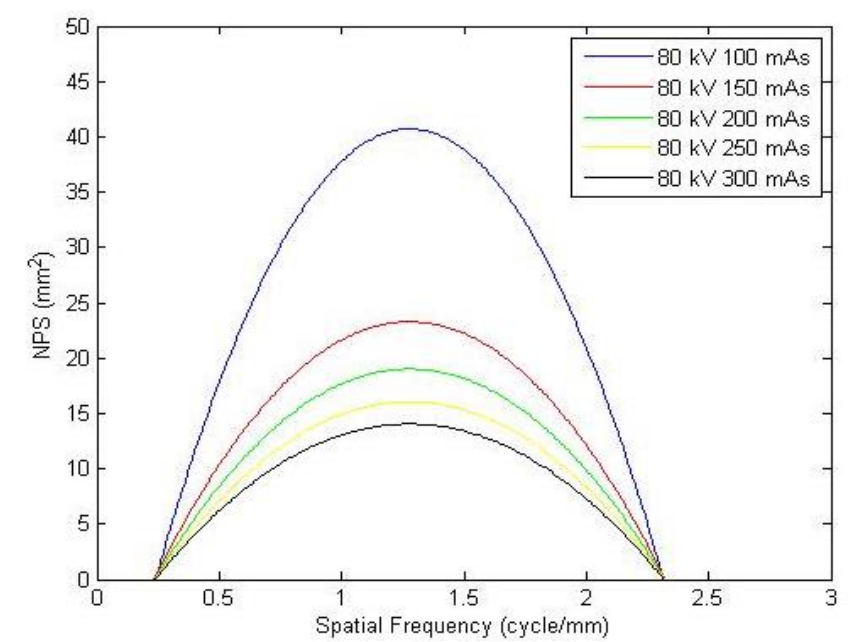

GAMBAR 4. Kurva noise power spectrum dengan satuan cycle $/ \mathrm{mm}^{2}$

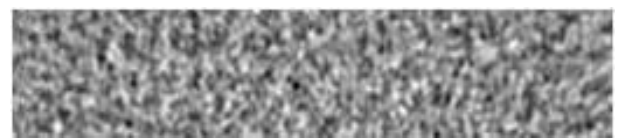

(a)

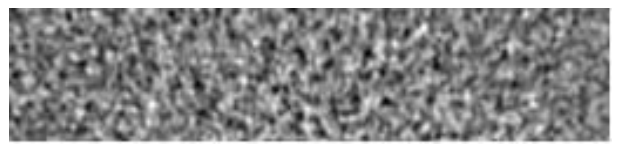

(c)

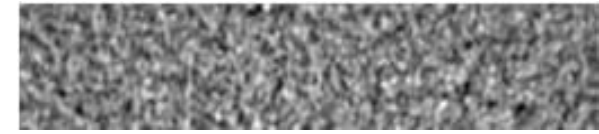

(b)

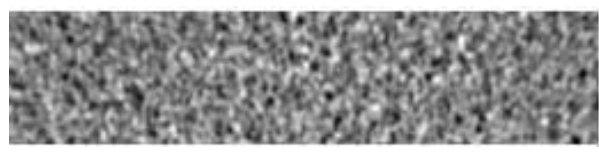

(d)

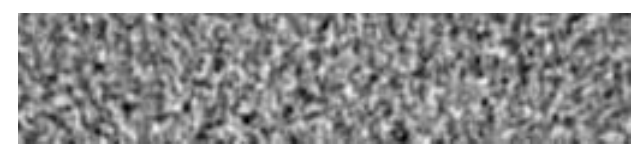

(e)

GAMBAR 5. Hasil citra sampel yang dipotong dengan ukuran 256x50 a). $130 \mathrm{kV} 100 \mathrm{mAs}, \mathrm{b}) .130 \mathrm{kV} 150$ mAs, c). $130 \mathrm{kV} 200 \mathrm{mAs}$, d). $130 \mathrm{kV} 250 \mathrm{mAs}$, e). $130 \mathrm{kV} 300 \mathrm{mAs}$.

Selanjutnya, dilakukan pengukuran NPS dengan melakukan transformasi fourier pada ratarata nilai piksel di tiap ROI. Kurva hasil pengukuran nps dapat dilihat pada gambar 4.7. sumbu X merupakan nilai dari NPS dan sumbu Y merupakan spatial frequency. Kurva pada gambar 4.7 merupakan kurva NPS dengan satuan piksel.

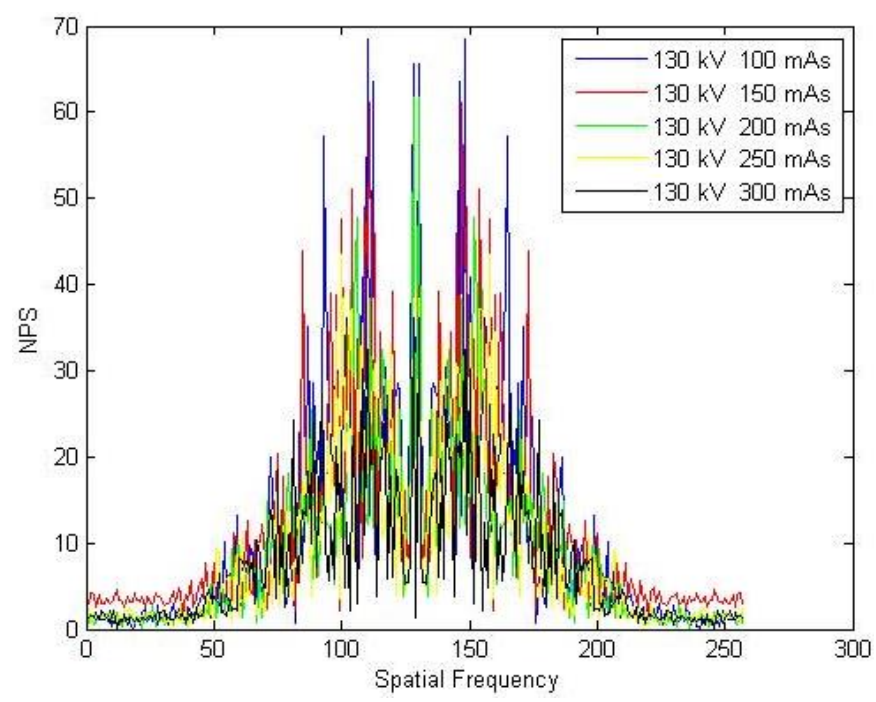

GAMBAR 6. Kurva noise power spectrum terhadap spatial frequency. 
Kurva NPS juga dapat dinyatakan dengan satuan NPS $\mathrm{mm}^{2}$ dan satuan spatial frequency cycle $/ \mathrm{mm}^{2}$ seperti pada gambar 7 .

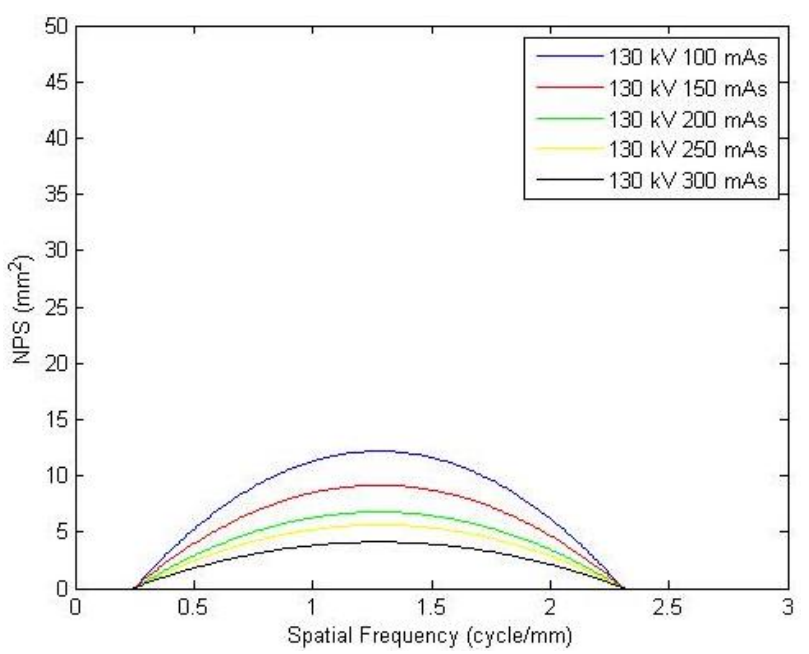

GAMBAR 7. Perbandingan noise power spectrum dari perubahan faktor eksposi $130 \mathrm{kV}$ dan variasi mAs.

Secara umum bentuk kurva NPS baik pada gambar 4 dan 7 bentuknya hampir sama yaitu terdapat 2 kemiringan kurva (slope). Kurva tersebut menjelaskan bagaimana sistem CTScan memproses variasi noise. Dapat terlihat pada kurva bahwa noise dengan spatial frequency rendah( ukuran besar) dan spatial frequency tinggi(ukuran kecil), yang berada diujung kanan kiri kurva memiliki NPS rendah, yang berarti noise tersebut tidak diproses secara maksimal oleh detektor. Noise dengan spatial frequency sedang (bagian tengah kurva) memiliki NPS tinggi yang berarti noise tersebut diproses secara maksimal oleh detektor.

Kemiringan pada spatial frequency rendah disebabkan dari ramp filtering yang digunakan dalam rekontruksi filter back projection pada CT-Scan [3]. Filter back projection menghasilkan citra yang kabur. Agar dapat memperoleh citra yang lebih detail digunakan filter tambahan yaitu ramp filtering. Filter tersebut merupakan high pass filter yaitu filter yang melewatkan sinyal dengan frekuensi tinggi, sehingga terdapat pengurangan sinyal noise pada frekuensi rendah [11]. Kemiringan kurva pada spatial frequency tinggi karena penggunaan rekontruksi kernel yang meredam noise dengan spatial frequency tinggi.

TABEL 1. Nilai mAs terhadap luas dibawah kurva NPS pada $80 \mathrm{kV}$ dan $130 \mathrm{kV}$.

\begin{tabular}{ccc}
\hline mAs & $\begin{array}{c}\text { Luas dibawah kurva NPS (varians) } \\
\text { pada } 80 \mathrm{kV}\end{array}$ & $\begin{array}{c}\text { Luas dibawah kurva NPS } \\
\text { (varians) pada 130 kV }\end{array}$ \\
\hline 100 & 5160 & 1519,2 \\
150 & 2988,5 & 1146 \\
200 & 2433 & 841,4 \\
250 & 2052,3 & 702,2 \\
300 & 1791,6 & 518,1 \\
\hline
\end{tabular}

Gambar 8 merupakan kurva NPS yang diperoleh dari citra Phantom dengan kV tetap yaitu $80 \mathrm{kV}$ dan variasi mAs yaitu $100 \mathrm{mAs}, 150 \mathrm{mAs}, 200 \mathrm{mAs}, 250 \mathrm{mAs}$ dan $300 \mathrm{mAs}$ bentuk kurva NPS pada tiap variasi mAs berbeda, semakin besar nilai mAs maka puncak kurva semakin rendah dan luas dibawah kurva semakin kecil. Kurva NPS dari citra Phantom dengan faktor eksposi $130 \mathrm{kV}$ dan $100 \mathrm{mAs}, 150 \mathrm{mAs}, 200 \mathrm{mAs}, 250 \mathrm{mAs}, 300 \mathrm{mAs}$ yang ditunjukkan pada gambar 7 juga menunjukkan kecenderungan yang sama. 
Luas dibawah kurva NPS sebanding dengan nilai varians $\left(\sigma^{2}\right)$. Nilai luas daerah dibawah kurva NPS terhadap perubahan mAs dapat dilihat pada gambar 8a dan 8b, semakin besar mAs semakin kecil luas dibawah kurva NPS.

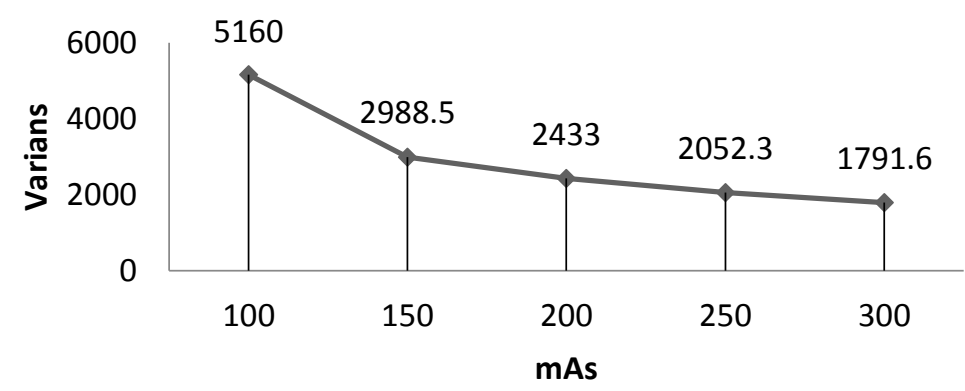

(a)

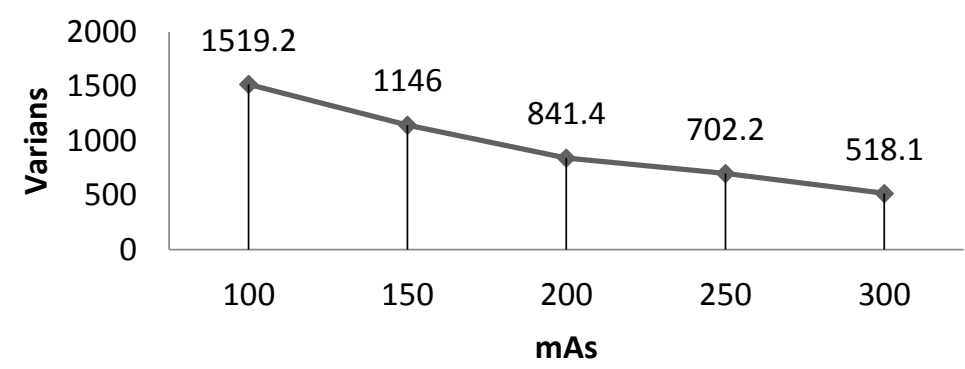

(b)

GAMBAR 8. Grafik varians (luas dibawah kurva NPS) terhadap mAs. a) Pada tegangan tabung 80 kV, b) pada teganga tabung $130 \mathrm{kV}$.

Nilai varians menunjukkan besarnya noise. Sehingga semakin besar nilai mAs semakin kecil noisenya. Penggunaan mAs yang besar mengurangi kuantum noise. Kuantum noise adalah noise yang disebabkan oleh sedikitnya jumlah foton (partikel sinar-x ) yang datang. Penggunaan $m$ As yang besar berarti terdapat banyak foton yang datang ke detekor sehingga jumlah kuantum noise berkurang. Selain itu, besarnya $\mathrm{kV}$ juga mempengaruhi nilai luas dibawah kurva NPS, seperti yang terlihat pada tabel 4.1 dan 4.2 kenaikan tegangan tabung dari $80 \mathrm{kV}$ ke $130 \mathrm{kV}$ pada mAs yang sama, mengurangi nilai luas dibawah kurva NPS. Sehingga semakin besar nilai $\mathrm{kV}$ semakin kecil noise.

\section{KESIMPULAN}

Berdasarkan hasil penelitian tentang analisis noise pada kualitas citra pada CT- Scan dengan menggunakan metode NPS yang diolah mengunakan software Matlab di Instalasi Radiologi RS Hermina Bekasi maka dapat disimpulkan bahwa : pada faktor eksposi $80 \mathrm{kV}$ dan variasi mAs $100 \mathrm{mAs}, 150 \mathrm{mAs}, 200 \mathrm{mAs}, 250 \mathrm{mAs}$, dan $300 \mathrm{mAs}$ semakin besar nilai mAs semakin rendah luas dibawah kurva NPS, yang berarti semakin rendah tingkat noise nya. Begitu juga pada faktor eksposi $130 \mathrm{kV}$ dan variasi mAs $100 \mathrm{mAs}, 150 \mathrm{mAs}, 200$ mAs, $250 \mathrm{mAs}$, dan $300 \mathrm{mAs}$ semakin besar nilai mAs semakin rendah luas dibawah kurva NPS, yang berarti semakin rendah tingkat noise nya. Dari data tersebut di dapat bahwa perubahan tegangan tabung dari $80 \mathrm{kV}$ ke $130 \mathrm{kV}$ mengurangi luas dibawah kurva NPS yang berarti semakin besar nilai $\mathrm{kV}$ semakin rendah tingkat noise. Selain itu, terlihat bahwa kurva NPS berbentuk parabola, dengan 2 kemiringan yaitu pada spatial frequency rendah dan spatial frequency tinggi, yang berarti sistem CT-Scan tidak memproses noise dengan spatial frequency rendah dan tinggi secara maksimal. Kurva NPS dapat digunakan untuk melihat tingkat noise dan tekstur noise. 


\section{DAFTAR PUSTAKA}

[1] F.R.Verduna, D.Racinea, J.G.Otta, M.J.Tapiovaara, P.Toroi, F.O.Bochud, W.J.H.Veldkamp, A.Schegerer, R.W.Bouwmand, I. Hernandez Giron, N.W.Marshall, S.Edyveang. Image quality in CT: From physical measurements to model observers. Physica Medica, Volume 31, Issue 8, December 2015, Pages 823843

[2] Bushberg, J. T, The Essential Phisics of Medical Imaging, ThirdEdition, Lippincot Williams \& Wilkins, Philadelphia.2012

[3] Riski, Nihayati. 2017. Analisis Kualitas Citra pada CT Scan Dengan Metode SNR (Signal to Noise Ratio) Menggunakan Software ImageJ. Universitas Nasional. 2017

[4] Radiation Dose And Image-Quality Assessment In Computed Tomography, Journal of the ICRU Vol 12 No 1 Report 87, Oxford University Press, 2012

[5] Solomon, J. B., Christianson, O., and Samei, E "Quantitative comparison of noise texture across CT scanners from different manufacturers," Med. Phys.9, 60486055, 2012.

[6] Friedman. N Saul, Fung S.K George, Siewerdsen. J. H, “A simple approach to measure computed tomography(CT) modulation transfer function(MTF) and noise power spectrum (NPS) using the american college of radiology(ACR) accreditation phantom",Med.Phys. 40(5), May 2013.

[7] Steven Dolly, Hsin-Chen Chen, Mark Anastasio, Sasa Mutic, Hua Li1. Practical considerations for noise power spectra estimation for clinical CT scanners. JOURNAL OF APPLIED CLINICAL MEDICAL PHYSICS, VOLUME 17, NUMBER 3, 2016

[8] Ricardo Betancourt Benitez, Ruola Ning, David Conover and Shaohua Liu. 2009. NPS characterization and evaluation of a cone beam CT breast imaging system. Journal of X-Ray Science and Technology 17, 17-40.

[9] L Rolstadaas and E Wasbø. 2018. Variations in MTF and NPS between CT scanners with two different IR algorithms and detectors. Biomedical Physics \& Engineering Express, Volume 4, Number 2.

[10] Jiwon, Choi. 2013. Measurement of Noise Power Spectra for CT Images Reconstructed with Different Kernels. Journal of Convergence Information Technology(JCIT), Volume8, Number 16.

[11] Gengsheng L. Zeng. 2015. Revisit of the Ramp Filter. IEEE TRANSACTIONS ON NUCLEAR SCIENCE, VOL. 62, NO. 1 